\title{
Dynamics of Dissolved Oxygen and Vertical Circulation in Fish Ponds
}

\author{
WILLIAM Y.B. CHANG ${ }^{1}$ and HAI OUYANG ${ }^{2}$ \\ ${ }^{1}$ Great Lakes Research Division, The University of Michigan, Ann Arbor, MI 48109 (U.S.A.) \\ ${ }^{2}$ Pearl River Fisheries Institute, Chinese Academy of Fisheries, Guangzhou (China)
}

(Accepted 29 March 1988)

\begin{abstract}
Chang, W.Y.B. and Hai Ouyang, 1988. Dynamics of dissolved oxygen and vertical circulation in fish ponds. Aquaculture, 74: 263-276.
\end{abstract}

Dissolved oxygen dynamics and vertical water circulation in high density integrated fish culture ponds were monitored monthly at 2-h intervals for $26 \mathrm{~h}$ from March through September at the Pearl River Delta, China. Stable thermal stratification was found almost daily in May-September. Vertical circulation began daily between 8 and 10 p.m. The average depth for this turnover in summer can be as great as $0.7-1 \mathrm{~m}$. Complete vertical circulation occurs only during major storms. A convection turbulence model was used to examine the vertical mixing process and showed that light wind $(<100 \mathrm{~cm} / \mathrm{s})$ and surface cooling $\left(<2^{\circ} \mathrm{C}\right)$ after sunset can substantially influence the depth of mixing.

Photosynthesis by algae is the most important natural mechanism contributing oxygen to ponds; compared to photosynthesis, net oxygen gain and loss due to diffusion during daylight is small. The compensation depth corresponded to twice the Secchi disk depth, ranging from 50 to $80 \mathrm{~cm}$. The dissolved oxygen (D.O.) concentration in the hypolimnion was usually less than $2 \mathrm{mg} / \mathrm{l}$, but increased at night during the period of vertical circulation. Hypolimnion oxygen deficit (HOD) was explored with the in situ D.O. concentration. HOD was found to increase during the daylight period and decrease at night after destratification.

\section{INTRODUCTION}

Adequate levels of dissolved oxygen (D.O.) are essential for maintaining optimal fish growth. Inadequate dissolved oxygen and poor water quality are frequently found in ponds receiving organic wastes and can lead to many serious problems for fish and further deterioration of water quality conditions in ponds; for example, with chronically low concentrations of D.O., fish do not feed or grow well. Fish and benthic organisms may die, water chemistry can be altered, and nitrite, ammonia and hydrogen sulfide concentrations can increase as anoxic conditions develop in the water (Chang, 1986).

Problems of low dissolved oxygen are particularly prevalent in ponds with 
high stocking densities of fish, and with large additions of organic wastes and feeds. Excess organic materials consume oxygen during decomposition and can drive D.O. in ponds to dangerously low levels should sudden destratification occur. The nutrients derived from organic waste and unused feed enhance algal growth. Dense growths of algae contribute large amounts of D.O. in ponds during the daylight period, resulting in super-saturation of oxygen in the epilimnion, but consume substantial quantities of oxygen at night causing anoxic conditions in pre-dawn hours (Schroeder, 1974; Boyd, 1982). When a major algal dieoff occurs, decomposition of algae creates low oxygen conditions (Swingle, 1968). Although the factors causing oxygen deficits, such as biological and chemical oxidation, microbial degradation and organism respiration, are discussed in Schroeder (1975), Boyd et al. (1978), Boyd (1982), and Chang et al. $(1983,1985)$, the dynamics of D.O. in ponds are largely unknown. This is especially true of vertical oxygen dynamics; there can be super-saturation of oxygen on the surface but oxygen can be depleted in the hypolimnion, even of shallow ponds. Data on such changes are either unavailable or measured at vertical increments so large that they are not applicable to oxygen dynamics in most culture ponds.

The research reported here was carried out in the Pearl River Delta, a most productive fish culture region of China. The maximum net production has reached $9750 \mathrm{~kg} / \mathrm{ha}$ per year, the highest production per unit area reported in China (Chang, 1987). Since the implementation of the Chinese new economic initiative in 1980, the demand for fish has increased substantially. Major cities such as Hong Kong and Guangzhou increasingly rely on pond production from the Delta to fill their need for fresh fish. The profit incentive has stimulated higher stocking densities and more intensive feeding regimes, resulting in more frequent oxygen depletion at dawn.

Vertical oxygen dynamics and water circulation were monitored and vertical water circulation was modelled using convection turbulence estimated by the Richardson number, $\mathrm{Ri}$ (Wetzel, 1975). The major elements which influence vertical oxygen dynamics in ponds and the relationship between water column stability, vertical water circulation, oxygen distribution, and hypolimnetic oxygen deficit are discussed.

\section{METHODS}

\section{Study area}

The experiments were conducted in ponds situated in the Pearl River Delta (lat. 114, long. 23) outside Guangzhou, Guangdong Province, China. The ponds in the Delta are shallow, averaging 1-2.5 $\mathrm{m}$ in depth, with $3 \mathrm{~m}$ being the maximum depth. Most (97\%) of the culture ponds are smaller than 1 ha (Chang, 
1985). Fish stocking densities were high, with a 1-ha pond generally stocked with 3000 grass carp (Ctenopharyngodon idella), 15000-45000 mud carp (Cirrhina molitorella), and 450-460 bighead (Aristichthys nobilis) or silver carp (Hypophthalmichthys molitrix). The primary culture practice was integrated polyculture with high stocking density, an intensive feeding regime, and rotations in harvesting. The rotation method is primarily used in ponds that can be drained. Ponds were stocked with up to three size-classes of each fish species. Fish of harvestable size were seined about every 2 months, and the same number of fingerlings were added to replace the fish removed (Chang, 1987). Ponds were aerated following overcast days to reduce the occurrence of anoxic conditions and the chance of mass fish mortalities at dawn. Where electricity was not available, aeration was often replaced by the addition of fresh water during the period of high tide. Salts were frequently spread in ponds to reduce the stress of nitrite toxicity during periods of low dissolved oxygen (Chang, 1986 ). Since electricity was available for the ponds selected for this study, fresh water was added only to maintain ponds at a constant depth and no fresh water was added during the week when the monthly oxygen experiments took place.

\section{Sampling methods}

Six 0.167-ha ponds were used for the study. One served as a control (no fish were stocked and no organic matter was added to the pond) while the others were stocked with fish at varying stocking densities. A sampling station was established at the center of each pond in March 1985. Vertical oxygen determinations were made at 2 - $\mathrm{h}$ intervals from $10 \mathrm{a} . \mathrm{m}$. on day 1 to noon the following day to cover a 26 -h oxygen cycle. Vertical oxygen determinations were carried out monthly during the culture period from March to September 1985. Samples were collected from the surface to the bottom of the ponds at $10-\mathrm{cm}$ intervals. A two-way $50-\mathrm{ml}$ syringe was used in connection with a portable vertical sampling device, to collect water at the various depths; the water collected at each depth was emptied directly into a sample bottle. The first two bottles of water were discarded to avoid errors from bubbles due to the use of the syringe and from water remaining in the sampling tubes. The portable vertical sampling device, which was placed in the pond 1 day before the experiment, was constructed from a $3-\mathrm{m}$ long bamboo pole. At about $60 \mathrm{~cm}$ from one end of the pole, rubber tubing was attached at $10 \mathrm{~cm}$ intervals, with a total of 20 pieces of tube attached altogether. The $60-\mathrm{cm}$ end was submerged in the sediment and the device was positioned such that the lowest tube was situated at the sediment surface. A T-shaped piece of glassware was attached to the end of each piece of tubing to facilitate the collection of water samples from the target depth without disturbing layers above and below the sampling point (Fig. 1).

Samples were collected starting from the surface and progressing to the bot- 


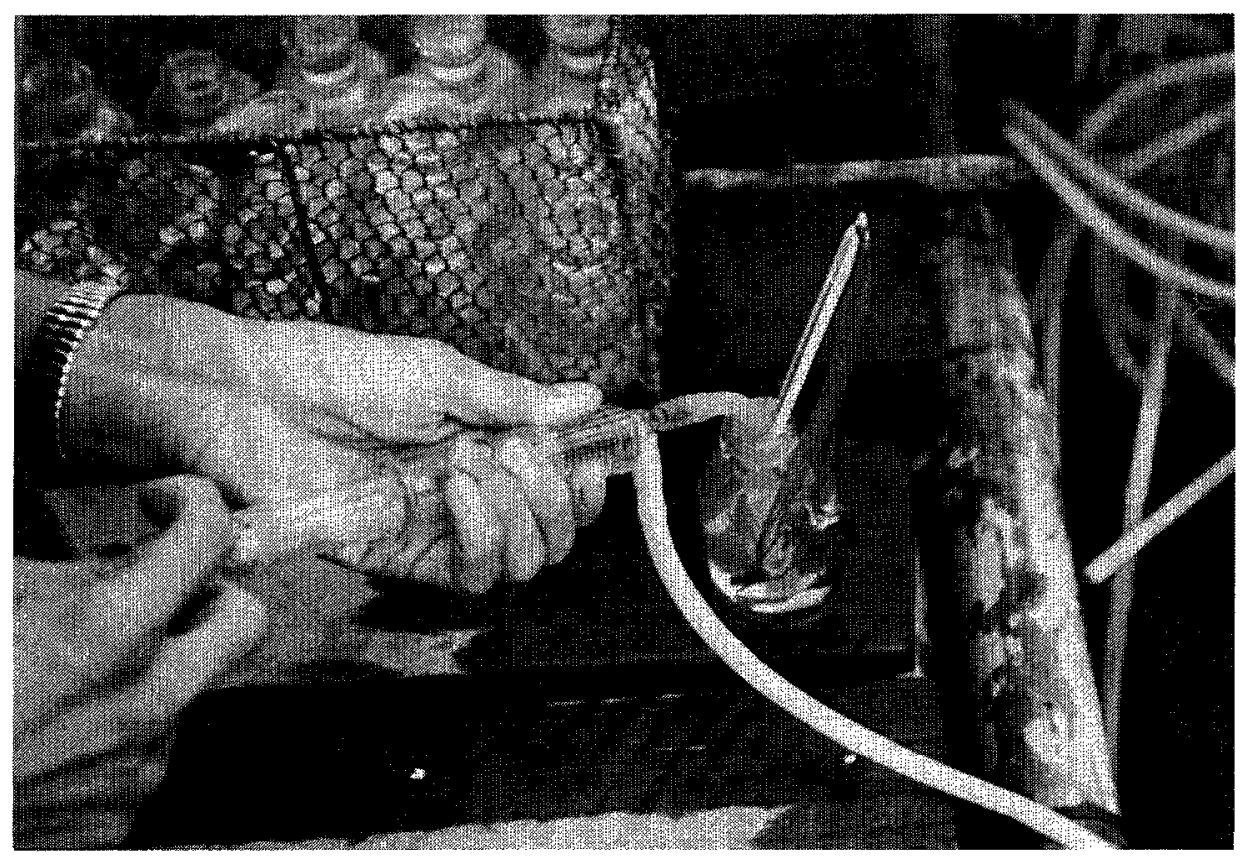

Fig. 1. The vertical sampling device and the method used for collecting water samples.

tom to minimize disturbance. Temperatures at each depth were recorded by placing a thermometer in a $250-\mathrm{ml}$ BOD sample bottle immediately after the water sample was released into it. The water samples were fixed immediately after the bottles were filled. The oxygen concentration was determined using the Winkler method (APHA, 1971). Concurrent light and dark bottle incubations were also performed each time D.O. was collected, for samples taken at the surface, $20 \mathrm{~cm}, 40 \mathrm{~cm}, 80 \mathrm{~cm}$, and the bottom. Wind speed was monitored at 2 -h intervals at the dike about $2 \mathrm{~m}$ above the water surface during the $26-\mathrm{h}$ sampling period, rainfall was measured during a 24 -h period and Secchi disk readings were taken twice a day during each incubation period.

\section{RESULTS}

\section{Thermal stratification}

Thermal stratification develops on any calm sunny day in the Delta, but persistent stable diel stratifications occurred between May and September. The diel stratification was especially marked on clear sunny days and was most stable from noon to $4 \mathrm{p} . \mathrm{m}$. It weakened and then disappeared at night as the upper layer cooled and water began to circulate vertically (Fig. 2). Three temperature zones, the epilimnion, the metalimnion and the hypolimnion, could 

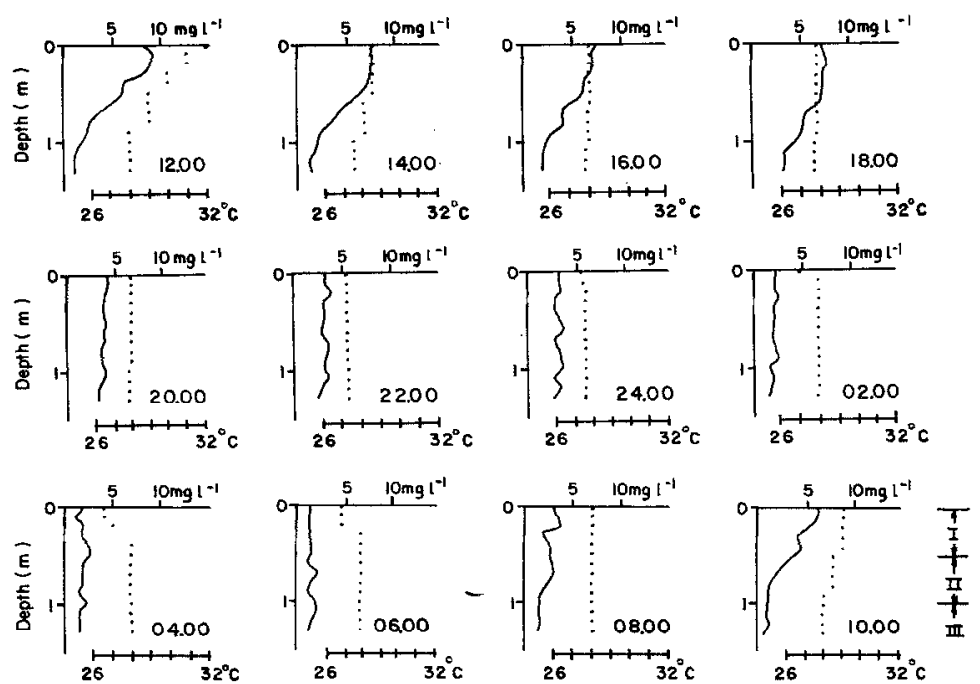

Fig. 2. The temperature and oxygen profiles of pond \#4, from 5 June 1985, an organically enriched integrated pond with a Secchi disk reading between 35 and $40 \mathrm{~cm}$, which had a high fish stocking density. These profiles represented a general pattern of temperature and oxygen changes in pond water in summer in the study area. The temperature zones of epilimnion, metalimnion, and hypolimnion were defined from the vertical profile where temperature difference is greater than $0.5^{\circ} \mathrm{C} / 10 \mathrm{~cm}$. I indicates epilimnion, II shows metalimnion, and III is hypolimnion. Solid lines represent dissolved oxygen concentrations $\left(\mathrm{mg} \mathrm{l}^{-1}\right)$; dotted lines represent temperature $\left({ }^{\circ} \mathrm{C}\right)$.

be identified from a stable stratification (see also Boyd, 1982; Fast, 1983), but the duration of the stratification and the thickness of the stratified layers differed substantially from those observed in natural lakes. Most ponds were smaller than $1 \mathrm{ha}$, shallow, and surrounded by high dikes, resulting in limited wind fetch and mixing. The three temperature zones found at midday were quite distinct and considerably compressed vertically. The sharp temperature gradient found in the metalimnion was as great as $1^{\circ} \mathrm{C} / 10 \mathrm{~cm}$. The midday epilimnion generally ranged from 30 to $70 \mathrm{~cm}$ depth, with the thickness of the layer directly related to wind speed and inversely related to the strength of solar radiance. Wind speed increased the vertical convection turbulence, producing an increase in vertical mixing which in turn resulted in a larger epilimnion. At limes, wind conditions also affected the thickness of the metalimnion. The hypolimnion was generally found below $1 \mathrm{~m}$. Here, only limited mixing occurred overnight; complete mixing occurred only during major storms.

Surface temperature of the ponds increased faster than in natural lakes. Solar radiance could heat the surface water and produce a stable water column within an hour in this area of China. On a windless, sunny day, a second thermal stratification often developed in the top $20 \mathrm{~cm}$, and temperature in this 
layer was often higher than the air temperature. Development of this layer provided additional stability in the vertical water column. It is frequently during this period that micro-surface layers develop.

\section{Vertical circulation}

The ponds generally circulated vertically overnight with vertical circulation beginning between 8 and $10 \mathrm{p} . \mathrm{m}$. The average depth in summer for this vertical turnover was as great as $0.7-1 \mathrm{~m}$ (Table 1 ). Complete vertical circulation (surface to bottom) does not occur frequently except during large storms. In areas where monsoon impact is strong, storms are one of the major factors influencing the vertical water circulation and oxygen distribution. However, uniform temperature profiles (an indication of circulation) frequently go unobserved if measurements are taken one or more hours after storms during daylight hours. Because solar radiation was generally strong and heated the epilimnetic water quickly, a new thermal stratification was frequently established in ponds within $1 \mathrm{~h}$ after major storms. The effects of storms on vertical circulation were frequently seen at night.

Vertical circulation can be modelled using convection turbulence, one of the major physical elements affecting vertical mixing. Convection turbulence can

\section{TABLE 1}

The predicted mixing depth $(\mathrm{cm})$ for different surface water temperatures, water temperature differences $(\mathrm{d} t / \mathrm{d} z)$, differences in densities between the surface and metalimnion and wind speed combinations. Water densities for $30^{\circ} \mathrm{C}$ and $15^{\circ} \mathrm{C}$ are $p\left(30^{\circ} \mathrm{C}\right)=0.9956756$ and $p\left(15^{\circ} \mathrm{C}\right)=0.9991265$

\begin{tabular}{|c|c|c|c|c|c|}
\hline \multirow{3}{*}{$\begin{array}{l}\text { Surface } \\
\text { temp. }\left({ }^{\circ} \mathrm{C}\right)\end{array}$} & \multirow{3}{*}{$\begin{array}{l}\text { Temp. }\left({ }^{\circ} \mathrm{C}\right) \\
\text { gradient }\end{array}$} & \multirow{3}{*}{$\begin{array}{l}\text { Density } \\
\text { gradient } \times 10^{5}\end{array}$} & \multicolumn{3}{|c|}{ Predicted mixing depth $(\mathrm{cm})$} \\
\hline & & & \multicolumn{3}{|c|}{ Wind speed $(\mathrm{cm} / \mathrm{s})$} \\
\hline & & & 50 & 100 & 200 \\
\hline \multirow[t]{7}{*}{30} & 5 & 140 & 2 & 4 & 9 \\
\hline & 4 & 114 & 3 & 5 & 10 \\
\hline & 3 & 87 & 3 & 7 & 14 \\
\hline & 2 & 59 & 5 & 10 & 20 \\
\hline & 1 & 30 & 10 & 20 & 39 \\
\hline & 0.5 & 15 & 20 & 39 & 78 \\
\hline & 0.2 & 6 & 48 & 97 & 194 \\
\hline \multirow[t]{7}{*}{15} & 5 & 60 & 5 & 10 & 20 \\
\hline & 4 & 51 & 6 & 12 & 23 \\
\hline & 3 & 40 & 7 & 15 & 29 \\
\hline & 2 & 28 & 11 & 21 & 42 \\
\hline & 1 & 14 & 20 & 41 & 81 \\
\hline & 0.5 & 7 & 40 & 80 & 159 \\
\hline & 0.2 & 3 & 101 & 203 & 405 \\
\hline
\end{tabular}


be studied using the Richardson number:

$\mathrm{Ri}=g \cdot(\mathrm{d} p / \mathrm{d} z) / p \cdot(\mathrm{d} u / \mathrm{d} z)^{2}$

where

$u=0.48 \cdot w^{0.5}$, current velocity $(\mathrm{cm} / \mathrm{s}) ; g=$ acceleration due to gravity, $980 \mathrm{~cm} /$ $\mathrm{s} ; p=$ water density; $z=$ mixing depth under consideration; $w=$ wind speed, $\mathrm{cm} /$ s.

Laminar flow was dominant in mixing; vertical mixing was slight and primarily a result of the diffusion process. If the Richardson number is greater than 0.25 , the water column is stable. When the Richardson number is smaller than 0.25 , the water circulates not only horizontally but also vertically, with convection turbulence playing a major role in the mixing (Hutchinson, 1957; Wetzel, 1975). Because mixing and gas exchange due to convection turbulence are several orders of magnitude larger than those of the diffusion process, the depth of convection turbulence is an indication of the extent of occurrence of major mixing in the water. Two important factors in the estimation of the Richardson number are water density, which is a function of water temperature, and wind conditions, which in this case include wind speed and the temperature of the wind.

In our simulation, surface water temperatures are assumed to be 15 and $30^{\circ} \mathrm{C}$, representing spring and summer temperatures, respectively. Since the magnitudes of the density difference for water of different temperatures increase with an increase of temperature, summer water temperatures have a higher stability than spring and fall water temperatures (Fig. 3). As a result, the same wind speed has a stronger vertical impact in spring and fall than in summer (Fig. 4). When the predicted mixing depths were compared with the depth of the thermocline (Table 2), we found that the model was sensitive to wind speed. Major crror may occur if point estimates of wind speed are used when the wind is shifty. Since variable wind conditions are often found in this region,

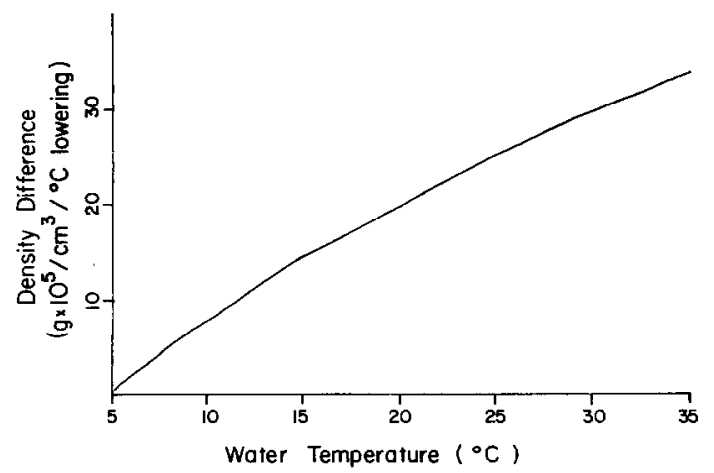

Fig. 3. Density difference per $1^{\circ} \mathrm{C}$ of temperature decrease. 


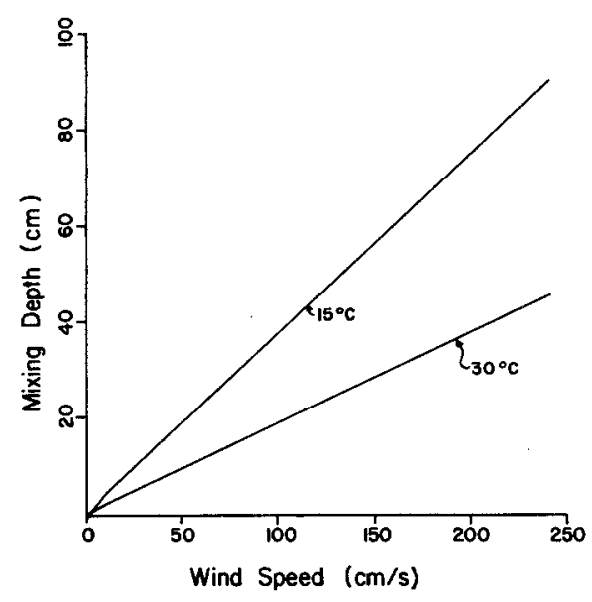

Fig. 4. The simulated mixing depths for various combinations of water temperature (summer, spring) and wind speed. One ${ }^{\circ} \mathrm{C}$ water temperature difference was assumed between the different vertical layers of water.

\section{TABLE 2}

The predicted mixing depths using the convection turbulence model compared to measured depths of the thermocline. The comparisons were made for six ponds where in situ wind speeds were available. Wind speeds were measured between 10 a.m. and 2 p.m., in 1985, at about $2 \mathrm{~m}$ above the water surface

\begin{tabular}{llllll}
\hline Date & $\begin{array}{l}\text { Air } \\
\text { temp. }\left({ }^{\circ} \mathrm{C}\right)\end{array}$ & $\begin{array}{l}\text { Temp. diff. } \\
\left({ }^{\circ} \mathrm{C}\right) \text { between } \\
\text { layers }\end{array}$ & $\begin{array}{l}\text { Wind } \\
\text { speed } \\
(\mathrm{cm} / \mathrm{s})\end{array}$ & $\begin{array}{l}\text { Predicted } \\
\text { mixing } \\
\text { depths }(\mathrm{cm})\end{array}$ & $\begin{array}{l}\text { Measured } \\
\text { thermocline } \\
\text { depth }(\mathrm{cm})\end{array}$ \\
\hline 3 April & 15 & $<0.1$ & $100-248$ & $>200$ & none \\
3 April & 15 & $<0.1$ & $100-248$ & $>200$ & none \\
5 April & 18 & 0.5 & $50-100$ & $39-79$ & $40-80$ \\
5 April & 18 & 0.8 & $50-100$ & $17-34$ & $20-40$ \\
1 April & 15 & 0.1 & $85-140$ & $>200$ & none \\
1 April & 15 & $<0.1$ & $85-140$ & $>200$ & none \\
5 June & 31 & 0.2 & $24-64$ & $23-62$ & $40-80$ \\
5 June & 31 & 1.0 & $24-64$ & $5-13$ & $10-30$ \\
2 July & 33 & 1.5 & $10-80$ & $2-16$ & $10-40$ \\
2 July & 33 & 0.5 & $10-80$ & $4-32$ & $20-40$ \\
\hline
\end{tabular}

continuous or range (minimum and maximum) recording of wind speeds appear to be a better estimate for describing the mixing process using this model. Furthermore, the in situ wind measurements (measured about $2 \mathrm{~m}$ above the water surface) were found to be substantially different for ponds located in the same general vicinity. The measurements made at the dike of a pond show the 
best agreement in estimating the mixing depth for the pond. The discrepancy can be large if the values are measured from other ponds in the study area. The location of ponds relative to large structures, such as buildings and dikes, appeared to be major factor in this respect. Based on the model simulation, overnight cooling of even 1 or $2^{\circ} \mathrm{C}$ on the water surface greatly extended the mixing depth, and a light wind $(<100 \mathrm{~cm} / \mathrm{s})$ contributed substantially to the mixing process (Table 1, Figs 3,4). The water density difference between spring and summer can influence markedly mixing layer depth and vertical temperature profiles (Fig. 4). This density difference is a result of temperature, because the water in the upper Pearl River Delta is fresh, with no seasonal salinity fluctuations.

\section{Oxygen dynamics}

Dissolved oxygen (D.O.) concentrations differed substantially with depth. During daylight hours, D.O. was super-saturated in the epilimnion while oxygen remained greatly under-saturated and often depleted in the hypolimnion (Fig. 2). The concentration gradient for D.O. was much greater than the temperature gradient and the greatest difference was found in the metalimnion. The lowest D.O. concentration was found in the hypolimnion and usually occurred during the midday period when solar radiation was high and thermal stratification strong. Dissolved oxygen in the hypolimnion was in general replenished at night when vertical circulation began. The hypolimnion D.O. concentration was rarely greater than $2 \mathrm{mg} / \mathrm{l}$.

Photosynthesis by algae is the most important natural mechanism contributing oxygen in ponds. Since most culture ponds are hyper-eutrophic with intensive growth of algae, the daytime dissolved oxygen in euphotic zones ranges from saturated to super-saturated except during heavily overcast days. Oxygen flow due to diffusion during the daylight period is negative, since the surface layer $(0-10 \mathrm{~cm})$ is generally super-saturated with D.O. The compensation depth corresponded to twice the Secchi disk depths and ranged from 50 to $80 \mathrm{~cm}$. The lower end of the euphotic zone in general corresponded to a sharp decline in dissolved oxygen, which frequently occurred in the metalimnion. However, turbulent mixing can change the positions of the metalimnion and the vertical D.O. profiles. Strong convection turbulence often reduced the D.O. and temperature gradient in the metalimnion. The major changes in the amount of D.O. were found in the top $80 \mathrm{~cm}$ and followed the intensity of solar radiance (see also Boyd et al., 1979; Romaire and Boyd, 1979). The maximum change in D.O. between day and night in a 24 -h period was as great as $10 \mathrm{~g} / \mathrm{l}$, while the gross change in the hypolimnion was usually less than $1 \mathrm{~g} / \mathrm{l}$ and was primarily due to D.O. input from vertical circulation at night. 


\section{DISCUSSION}

Oxygen dynamics in ponds differ substantially from those in natural aquatic systems, since pond environments are smaller in area and shallower in depth with limited water circulation. Photosynthesis is the most important factor contributing oxygen to the system and is directly influenced by the amount of solar radiation and algal density. Differences in dissolved oxygen in the epilimnion between an overcast and a clear day are considerable, at times exceeding $5 \mathrm{~g} / \mathrm{l}$. The super-saturation of oxygen usually occurs in the euphotic zone during the daylight period, particularly in the top $20-30 \mathrm{~cm}$ of pond water. As a result, there is a net diffusion of oxygen from the water to the air. The oxygen concentration in the euphotic zone also shows great diurnal variation, mainly due to algal photosynthesis and respiration. This variation is often accentuated in ponds with high algal biomass. Since algal biomass has a significant impact on photosynthesis, it also affects the vertical dissolved oxygen profile. It contributes D.O. to the euphotic zone (primarily in the epilimnion) and consumes D.O. in the hypolimnion, with a D.O. balance between consumption and production in the metalimnion. High algal biomass in ponds produces a greater range between oxygen concentrations in the epilimnion and those in the hypolimnion. Hepher (1962) stated that as fish ponds become more enriched with nutrients, primary productivity increases in the upper layers of water where favorable light conditions exist, but decreases in the lower layers where overshading by plankton reduces light penetration. However, total oxygen production per unit surface area $\left(\mathrm{m}^{2}\right)$, after an initial phase of increase such as the pond filling stage, usually reaches an equilibrium. The total oxygen production per unit area does not very greatly with increases in algal biomass since the increase of algal biomass results in a higher production of oxygen in the upper epilimnion and is balanced by a reduction in compensation depth and in oxygen production at the lower depth due to algal self-shading.

Integrated ponds are hyper-eutrophic and receive a great deal of enrichment, almost daily, which encourages the growth of blue-green and green algae. Since many species of blue-green algae have higher buoyancy than water, they can float on the water surface and form an extensive surface microlayer at the airwater interface, often not more than a few millimeters thick (Hardy, 1973). The development of this surface microlayer in ponds is very noticeable on days when the wind is low and solar radiation is strong. The blue-green algae rise to the surface as a consequence of their "gas vacuoles" and aggregate into thick masses (Ruttner, 1969; Wetzel, 1975). The formation of this layer can also be aided by the rising gases from the super-saturated oxygen in the water, which entrap plankton, microorganisms, and detritus remnants and transport them to the surface layer. Genera such as Microcystis and Anabaena are frequently found in this mass. Little or no dissolved oxygen may be contributed by the surface algal layer, since it floats on the air-water interface, although no data 
were obtained to substantiate this belief. This microlayer can also substantially reduce the wind-driven water mixing and inhibit the diffusion of oxygen from and to the pond water. The newston (a term used for the organisms living in the surface layer) are not yet well understood since general pond sampling has often missed this group, although the newston and the surface microlayer effect have an important impact on the pond.

Oxygen depletion in the hypolimnion is found in most integrated ponds. Thermal stratification in ponds develops during the daylight period, and weakens or disappears at night when water circulates vertically. Little or no oxygen is added to the hypolimnion during daylight, but the consumption of oxygen continues to produce the lowest hypolimnetic oxygen concentrations. Dissolved oxygen is infused to the hypolimnion by vertical circulation at night, but this increase of D.O. also results in an increase in the rate of oxygen consumption. Wong (1984) indicated that the rate of oxygen consumption by oxidizable matter in water is dependent on the dissolved oxygen concentration in water as shown in equation 2 ,

D.O. consump. $(\mathrm{mg} / \mathrm{l}$ per h $)=0.149 *(\text { D.O. conc. })^{0.668}$

(Eqn. 2)

The rate of oxygen consumption by oxidizable matter is three times higher when D.O. is $5 \mathrm{mg} / \mathrm{l}$ than when D.O. is $1 \mathrm{mg} / \mathrm{l}$. The relationship between rate of increase in oxygen consumption by oxidizable matter and D.O. in the water is different for different pond environments, but the near linear relationship between the rate of oxygen consumption and D.O. concentration in low D.O. environments has been found to be true for most culture environments. For example, a similar relationship between the D.O. concentration and the oxygen consumption was found from the $24-\mathrm{h}$ dark bottle incubation conducted in this study, in which we found the percentage of change in oxygen consumption by oxidizable material for D.O. at $5 \mathrm{mg} / \mathrm{l}$ and $1 \mathrm{mg} / \mathrm{l}$ was almost the same as the change noted by Wong (1984). A difference in magnitude was, however, found between the values derived from eqn. 2 and this study. Eqn. 2 gives a rate of $0.46 \mathrm{mg} / \mathrm{l}$ per h when D.O. is $5 \mathrm{mg} / \mathrm{l}$, and $0.15 \mathrm{mg} / \mathrm{l}$ per $\mathrm{h}$ when D.O. is $1 \mathrm{mg} / \mathrm{l}$. We found a rate of $0.19 \mathrm{mg} / \mathrm{l}$ per $\mathrm{h}$ when D.O. was $5 \mathrm{mg} / \mathrm{l}$ and 0.06 when D.O. was close to $1 \mathrm{mg} / \mathrm{l}$. The absolute rates derived from this study are substantially lower than those from eqn. 2 . The reason for this difference may be due to the length of incubation. A 24-h incubation was used in this study as compared to a 4-h incubation in the study conducted by Wong (1984). As a result, the rates were lower for a 24-h incubation due to the dependent relationship between D.O. and oxygen consumption.

Because of the incomplete oxidation in the low D.O. ( $<5 \mathrm{mg} / 1)$ hypolimnetic pond environment, potential consumption of oxygen (the rate of oxygen consumption if D.O. is maintained at $5 \mathrm{mg} / 1$ or greater) increases in the daylight period in the hypolimnion and becomes highest during the midday period when the D.O. concentration is the lowest, as shown in Fig. 5. This figure 


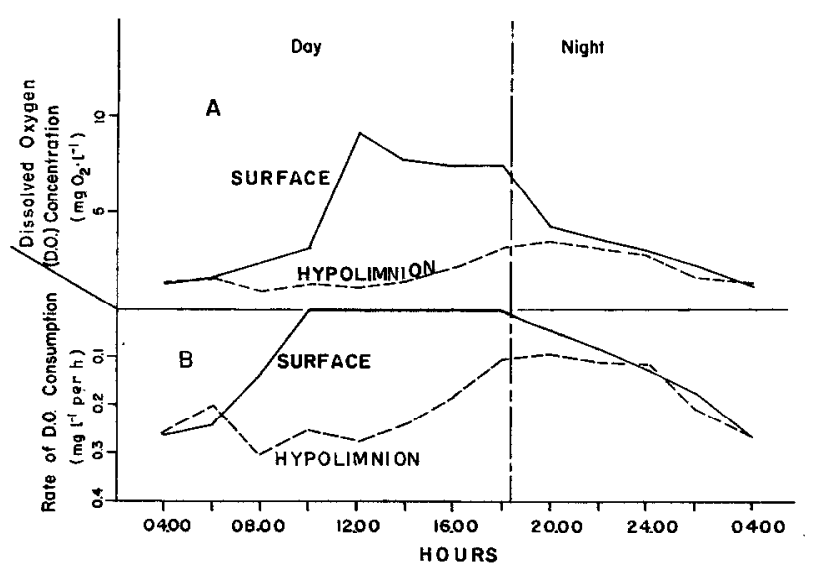

Fig. 5. (A) Dissolved oxygen concentration (mg/l) in the surface water $(0-10 \mathrm{~cm})$ and hypolimnetic water $(>1 \mathrm{~m})$. (B) The corresponding rate of potential dissolved oxygen consumption for surface and bottom water, if the dissolved oxygen concentration is $5 \mathrm{mg} / \mathrm{l}$ or higher. Solid lines indicate surface water and dotted lines indicate hypolimnetic water.

represents an example of the diurnal changes in potential oxygen consumption by oxidizable matter in ponds, and was derived from eqn. 2 using the D.O. values from the top $10 \mathrm{~cm}$ and from lower than $1 \mathrm{~m}$. The potential hypolimnetic oxygen consumption is large and has an impact on the oxygen budget in ponds. It is one of the major reasons why a rapid vertical circulation often drives the D.O. concentration in water dangerously low.

The rate of increase in oxygen consumption is also dependent on $\mathrm{pH}$ and temperature (Wong, 1984), where the relationship for $\mathrm{pH}$ and the rate of oxygen consumption peaks at a $\mathrm{pH}$ around 8 and a linear increase between temperature and the rate of increase in oxygen consumption is noted for temperatures less than $35^{\circ} \mathrm{C}$. The impact of changes in $\mathrm{pH}$ and temperature on potential hypolimnetic oxygen consumption is small, since $\mathrm{pH}$ and temperature in the hypolimnion are fairly constant. Maximum daily changes in hypolimnetic temperature are not more than 2 or 3 degrees and $\mathrm{pH}$ generally ranges from 7 to 8 . Oxygen consumption by mud, on the other hand, is greatly dependent on the D.O. concentration. The rate of D.O. consumption is $2 \mathrm{mg} /$ $l$ per $h$ for a D.O. concentration of $5 \mathrm{mg} / \mathrm{l}$ and is reduced to $0.1 \mathrm{mg} / \mathrm{l}$ per $\mathrm{h}$ when the D.O. is less than $0.5 \mathrm{mg} / \mathrm{l}$. These rates are more than doubled if the mud is stirred periodically.

Dissolved oxygen has a significant impact on fish culture, although attention has rarely been given to its vertical distribution in ponds, the vertical difference between production and consumption of D.O., the efficient use of photosynthetically produced oxygen in the epilimnion, or the potential oxygen consumption in the hypolimnion. An integrated culture pond is frequently hyper-eutrophic. Dissolved oxygen is depleted in the hypolimnion and is super- 
saturated in the epilimnion where saturated D.O. diffuses out of the pond under slight disturbance. This super-saturated D.O. can be used to improve hypolimnetic D.O. conditions and to reduce the hypolimnetic oxygen deficit. This method was applied in the culture ponds in the Pearl River Delta where aerators were used during midday hours on clear days to circulate the water vertically without breaking the surface water tension. There was a significant improvement in hypolimnetic oxygen conditions and a reduction in the severity of anoxic conditions during the early morning hours on the following day. The circulation of pond water during midday hours on clear days also reduced the hypolimnetic oxygen deficit and the major fish kills that occur frequently during sudden turnovers brought about by major storms.

\section{ACKNOWLEDGMENTS}

The study was supported by the CSCPRC, National Academy of Sciences, and by a grant (no. DAN-4023-G-SS-2074-00) from the Pond Dynamics/ Aquaculture Collaborative Research Support Program (CRSP), Agency for International Development. The matching funds for the grant were provided by the Office of Vice President for Research, The University of Michigan. Helpful comments from Drs. Arlo Fast, Kevin Hopkins, David Jude, and Raul Piedrahita are gratefully acknowledged. The authors also thank the anonymous reviewers for helpful suggestions and comments. The authors are particularly indebted to the Pearl River Fisheries Research Institute, Chinese Academy of Fisheries Sciences, for providing financial and logistic assistance for this research. We are grateful for the participation of Hwang Zanghun, Wu Zuiquan, Lim Moonhu, Lu Maixin, Lu Xiaodan, and Zhang Rongjian in the 26 - $h$ continuous D.O. measurements, and appreciate the guidance provided by Professor Zhong Lin and Mr. Liu Jiazhao.

\section{REFERENCES}

APHA, 1971. Standard Methods. American Public Health Association, Washington, DC, 874 pp.

Boyd, C.E., 1982. Water Quality Management for Pond Fish Culture. Elsevier, New York, NY, $318 \mathrm{pp}$.

Boyd, C.E., Romaire, R.P.. and Johnson, E., 1978. Predicting early morning dissolved oxygen concentration in channel catfish ponds. Trans. Am. Fish. Soc., 107 (3): 484-492.

Boyd, C.E., Romaire, R.P. and Johnson, E., 1979, Water quality in channel catfish production ponds. J. Environ. Qual., 8(3): 423-429.

Chang, W.Y.B., 1985. Pond fish culture in the Pearl River Delta. Aquacult. Mag., 11(4): 45-46.

Chang, W.Y.B., 1986. Practical methods for treating fish during oxygen stress in ponds. Aquacult. Mag., 12(1): 20-21.

Chang, W.Y.B., 1987. Fish Culture in China. Fisheries, $12(3): 11-15$.

Chang, W.Y.B., Diana, J. and Chuapoehuk, W., 1983. Strengthening of Southeast Asia Aquaculture Institutions. Workshop Report to Agency for International Development. Great Lakes Research Division, University of Michigan, Ann Arbor, MI, 225 pp. 
Chang, W.Y.B., Diana, J.S. and Chuapoehuk, W., 1985. Modelling production systems for commonly cultured fishes of Southeast Asia. Proc. 2nd Int. Conf. on Warm Water Aquaculture. Brigham Young Univ., Kahana, Hawaii, pp. 269-290.

Fast, A.W., 1983. Pond production systems: water quality management practices. In: J.E. Lannan, R.O. Smitherman and G.T. Tchobanoglous (Editors), Principles and Practices of Pond Aquaculture: a State of the Art Review. Oregon State Univ. Press, Corvallis, OR, pp. 145-165.

Hardy, J.T., 1973. Phytoneuston ecology of a temperate marine lagoon. Limnol. Oceanogr., 18: 525-53.

Hepher, B., 1962. Primary production in fish ponds and its application to fertilization experiments. Limnol. Oceanogr., 7: 131-135.

Hutchinson, G.E., 1957. A Treatise on Limnology. Vol. 1. John Wiley, New York, NY, 1015 pp.

Romaire, R.P. and Boyd, C.E., 1979. Effects of solar radiation on the dynamics of dissolved oxygen in channel catfish ponds. Trans. Am. Fish. Soc., 108: 473-478.

Ruttner, F., 1969. Fundamentals of Limnology. (Translated by D.G. Frey and F.E.J. Fry). Univ. of Toronto Press, Toronto, 295 pp.

Schroeder, G.L., 1974. Use of fluid cowshed manure in fish ponds. Bamidgeh, 26: 84-96.

Schroeder, G.L., 1975. Nighttime material balance for oxygen in fish ponds receiving organic wastes. Bamidgeh, 27: 65-74.

Swingle, H.S., 1968. Fish kills caused by phytoplankton blooms and their prevention. FAO United Nations Fish. Rep., 44(5): 407-411.

Wetzel, R.G., 1975. Limnology. Saunders, Philadelphia, PA, 744 pp.

Wong, W. 1984. Oxygen consumption and deficit in intensive culture ponds. In: Principles and Techniques in High Production Pond Aquaculture. Shanghai Fisheries College Press, Shanghai, China, pp. 44-59. 